\title{
WIDUKIND, THIETMAR, THIDDAG: SPUREN DER SACHSENMISSION IN BÖHMEN
}

\author{
JAKUB IZDNÝ \\ Philosophische Fakultät, Karls-Universität, Prag \\ E-mail: jakub.izdny@ff.cuni.cz
}

\begin{abstract}
Widukind, Thietmar, Thiddag: The Traces of a Saxon Mission in Bohemia

The aim of this article is to investigate the information about the possible Saxon-Bohemian contacts in the missionary field during the 10th and in the beginning of the 11th century. Although the Bavarian contacts are probably rightfully considered important and crucial in the current picture of Christianization of Bohemia, there are interesting facts that support the possibility, that the Saxons played an important role in the forming of Bohemian Christianity, too. The first and third bishops of Prague were of Saxon descent and even the fourth bishop originated from the similar region. The main church of Prague was dedicated to St. Vitus, who could also be connected with the Saxon area and the Corvey monastery in particular. The Corvey monastery could serve as a possible missionary centre.
\end{abstract}

Keywords: Bohemia; Bavaria; Saxony; mission; Christianization

Die die Anfänge des tschechischen Staats diskutierende Historiographie fasst liudolfingisch-ottonisches Sachsen als eine langzeitige Nemesis der přemyslidischen Herrscher auf. In der Tradition des Verständnisses der tschechischen Geschichte als eines Kampfes zwischen dem tschechischen (slawischen) und dem germanischen (deutschen) Element kann es vielleicht nicht anders sein ${ }^{1}$. Die "große" Geschichte des přemyslidischen 10. Jahrhunderts neigt dazu, sich um die neuralgischen Punkte der Jahre 929, 936 und $950 \mathrm{zu}$ versammeln. Es geht immer mehr oder weniger um ein militärisches Engagement der Tschechen mit den sächsischen Truppen (obwohl die tatsächlichen Kämpfe in den Quellen nur für das mittlere Datum beschrieben sind), die die Lage des tschechischen Staates in christlichem Europa für eine lange Zeit verändert oder gar definiert haben sollten $^{2}$. Aus unserer Sicht ex eventu ging der tschechische Staat auf eine langfristige und gezwungene Koexistenz mit den mächtigen Herrschern des Heiligen Römischen Reiches ein. Die Vorstellung, dass Sachsen ein Gebiet sei, aus dem die christliche Kultur

1 Es ist eigentlich so von Palacký (František PALACKÝ, Geschichte von Böhmen: grösstentheils nach Urkunden und Handschriften. Band 1: Die Urgeschichte und die Zeit der Herzoge in Böhmen bis zum Jahre 1197. Prag 1836) bis zu Třeštík (Dušan TřEŠTÍK, Počátky Přemyslovcư: vstup Čechů do dějin (530-935). Praha 1997).

2 Alle sind beschreibt im Widukinds Chronik: Widukindi monachi Corbeienses Rerum gestarum Saxonicarum libri III, neu bearb. von Paul HIRSCH - Hans-Eberhard LOHMANN (MGH Scriptores rerum Germanicarum in usum scholarum separatim editi. Bd. 60). Hannover 1935, S. 50 f., 68 ff. und 108 f. (I 35; II 3 und III 7). 
in Böhmen eingetreten sei, und damit auch der fortschreitende Trend der mittelalterlichen europäischen Entwicklung, ist in diesen Texten ganz verkannt, wenn sie überhaupt vorkommt.

Das Verständnis des 10. Jahrhunderts als einer Periode des ständigen tschechischsächsischen Konflikts geht so weit, dass die späteren komplizierten Verhältnisse der tschechischen Herrscher zum zukünftigen germanischen Hegemonen schon lange vor der endgültigen Konsolidierung und Stabilisierung der ottonischen Macht in der Mitte des 10. Jahrhunderts in alle Ereignisse projiziert werden. Der große Konflikt wird also auch damals vorausgesetzt, als der tschechisch-sächsische modus vivendi nicht nur gesucht wurde, sondern auch als er im Rahmen des Schwungs der Macht der böhmischen Boleslaven in der zweiten Hälfte des 10. Jahrhunderts eine völlig andere Form gewinnen konnte. Der erwartete tschechisch-sächsische Zusammenstoß belastet auch das Bild der politischen Geschichte des Anfangs des 10. Jahrhunderts, als die sächsische Hegemonie nur von einem sehr fähigen Propheten vorausgesetzt werden konnte. ${ }^{3}$ Die Liudolfinger waren aber zu dieser Zeit eher in der Defensive gegenüber der politischen Clique von dem Erzbischof Hatto ${ }^{4}$. Ein wichtiger Teil dieser Clique waren die fränkischen Konradiner, die sich gerade ihrer lokalen Konkurrenten, Babenberger, erfolgreich und rücksichtslos entledigt haben ${ }^{5}$. Die Babenberger waren Verwandten und scheinbar auch Verbündete des Herzogs Otto von Sachsen. Auf der Szene war noch auch eine - später fast vergessene Persönlichkeit des thüringischen Herzogs Burkhard, der auch ein großer Konkurrent von Ottonen in der Gegend war, bevor er zum Opfer von ungarischen Überfällen wurde ${ }^{6}$. Der damalige Zusammenstoß zwischen den Daleminzier und Sachsen ${ }^{7}$, der manchmal als Beginn der sächsischen Expansion gilt, scheint dazu über das Interesse der Geschichtsschreiber hinausgegangen zu sein, wenn der Beginn der ungarischen Angriffe im Norden des Reiches nicht mit ihm verbunden war. Diese Angriffe haben allerdings die Chance der Ottonen auf die Hegemonie im mitteleuropäischen Raum wieder verringert.

Der Beginn des 10. Jahrhunderts musste für die Tschechen in Bezug auf germanische Nachbarn vor allem politische und religiöse Orientierung auf Bayern bedeuten. Im Jahre 895 unterwarfen sich die tschechischen Fürsten Spytihněv und Vitislav dem ostfränkischen König ${ }^{8}$, um die enge Beziehung zu Mähren zu unterbrechen, was für die gesamte zweite Hälfte des 9. Jahrhunderts sehr charakteristisch war ${ }^{9}$. Weitere Veränderungen der politischen Situation haben diese Entscheidung zu einem Eckpfeiler aller weiteren politischen Entwicklungen gemacht. Der König und später Kaiser Arnulf von Kärnten reprä-

3 Vor allem TřEŠTíK, Počátky Přemyslovců, S. $361 \mathrm{f}$.

4 Vgl. Widukindi monachi Corbeienses Rerum gestarum Saxonicarum, S. 30-35 (I 22) und zum Beispiel Helmut BEUMANN, Die Ottonen. Stuttgart/Berlin/Köln 2000, S. 24-26.

5 Wilhelm STÖRMER, Die konradinisch-babenbergische Fehde um 900: Ursachen, Anlaß, Folgen, in: Hans-Werner Goetz - Simon Elling (Hgg.), Konrad I.: auf dem Weg zum Deutschen Reich?. Bochum 2006, S. 169-184.

6 Siehe Hans PATZE, Burchard, Graf und Markgraf von Thüringen († 909), in: Lexikon des Mittelalters 2 (2003), Sp. 942.

7 Widukindi monachi Corbeienses Rerum gestarum Saxonicarum, S. 27-30 (I 17 und I 20).

8 Annales Fuldenses sive Annales regni Francorum orientalis, hg. von Friedrich KURZE (MGH Scriptores rerum Germanicarum in usum scholarum separatim editi. Bd. 7). Hannover 1891, S. 126 (a. 895).

9 Siehe z. B. Dušan TŘEŠTÍK, Bořivoj und Svatopluk: die Entstehung des böhmischen Staates und Großmähren, in: Josef Poulík - Bohuslav Chropovský (Hgg.), Grossmähren und die Anfänge der tschechoslowakischen Staatlichkeit. Praha 1986, S. 311-344. 
sentierte für die Tschechen seit langem offensichtlich nicht nur das Reich, sondern auch die bayerische Souveränität, und es scheint, dass neben den tschechisch-mährischen Kontakten auch die tschechisch-bayerischen Kontakte im böhmischen politischen Leben eine natürliche Rolle gespielt haben. Die Bayerische Seite hat dieses Ereignis außerdem als eine Erneuerung der ursprünglichen, sagen wir mal natürlichen Beziehung wahrgenommen. Das Jahr 895 wird in der tschechischen historischen Literatur als Beginn der eindeutigen Integration des böhmischen Beckens in die kirchliche Verwaltung des bayerischen Bistums von Regensburg verstanden ${ }^{10}$. Die spätere Hagiographie, die den Beginn des Christentums in Böhmen beschreibt, betrachtet Spytihněv als den ersten getauften Fürsten, was diese These zu bestätigen scheint ${ }^{11}$. Eigentlich können wir auch erwarten, dass Böhmen unter dem Einfluss der bayerischen Kirche schon im 9. Jahrhundert stand, und es ist sogar möglich, einige sporadische Missionen vorauszusetzen, die diesem Jahr vorausgingen. Es ist möglich, sie wenigstens mit der rätselhaften Taufe von $845^{12} \mathrm{zu}$ verbinden, die aber schließlich in der Tradition der Kirchengeschichte von Böhmen nicht fest verzeichnet wurde ${ }^{13}$. Die bayerischen Priester mussten so im Jahr 895 in Böhmen keine wirklichen Anfänger sein. Die Regierung von Spytihněv I ist mit dem Bau der Kirchen verbunden, wahrscheinlich mit dem Beginn der ersten stabilen Organisation der Kirche, möglicherweise mit dem Aufstieg des ersten provisorischen Pfarrnetzes, das mit den Přemyslid-Burgen in Mittelböhmen verbunden sein konnte ${ }^{14}$. Wurden diese Kirchen nicht von Emigranten aus Mähren besetzt, wovon auch allgemein die tschechische Literatur überzeugt ist (obwohl das Ausmaß ihres Einflusses auf die tschechische Kirche noch diskutiert wird $)^{15}$, war es höchstwahrscheinlich der bayerische Klerus, der sich um diese ersten Stiftungen kümmerte ${ }^{16}$. Und es sollte betont werden, dass der bayerische Einfluss nicht einmal von der möglichen Kontinuität des slawischen Kirchenlebens verringert wurde. Der Gebrauch der „slawischen Sprache“ im pastoralen Dienst könnte auch für bayerische Missionare möglich sein und schließlich die ankommenden Priester aus Mähren mussten offensichtlich früher oder später dem Gehorsam von Regensburg zu-

10 Dušan TŘEŠTíK, Od příchodu Slovanů k „říši“ českých Boleslavů, in: Petr Sommer - Dušan Třeštík Josef Žemlička (Hgg.), Přemyslovci: budování českého státu. Praha 2009, S. 61-96; hier S. 88. Der sogenannte Christian (Legenda Christiani: vita et passio Sancti Wenceslai et sancte Ludmile ave eis = Kristiánova legenda: život a umučení svatého Václava a jeho báby svaté Ludmily, hg. von Jaroslav LUDVÍKOVSKÝ. Praha 1978, S. 52 f. und auch Gumpold von Mantua (Vita Vencezlavi ducis Bohemiae, hg. von Josef EMLER, Fontes rerum bohemicarum. Bd 1. Praha 1873, S. 146-166; hier S. 157 [Kap. 15]) bestätigen die Zuständigkeit Böhmens zu dem Regensburger Bistum eindeutig nur für die Zeit des Wenzels.

11 Siehe die „bayerische“ Redaktion der Legende Crescente fide Christiana. Recensio bavarica, hg. von Josef EMLER, Fontes rerum bohemicarum. Bd. 1, Praha 1873, S. 183-190; hier S. 183. So auch Vita Vencezlavi ducis Bohemiae, S. 148 (Kap. 2).

12 Siehe Annales Fuldenses sive Annales regni Francorum orientalis, S. 35 (a. 845).

13 Diese Theorien waren jüngst nochmal diskutiert im Sammelbuch Ivo ŠTEFAN - Martin WIHODA (Hgg.), Kostel Panny Marie na Pražském hradě: dialog nad počátky křestanstvív Čechách. Praha 2018.

14 Dieses System ist von Jiří SLÁMA (Střední Čechy v raném středověku. Bd. 3: Archeologie o počátcích premyslovského státu. Praha 1988) vorausgesetzt.

15 Zum letzten Mal Ivo ŠTEFAN, Velká Morava, počátky přemyslovských Čech a problém kulturní změny, in: Jiř́ Macháček - Martin Wihoda (Hgg.), Pád Velké Moravy aneb Kdo byl pohřben v hrobu 153 na Pohansku u Břeclavi. Praha 2016, S. 190-231; hier S. 215-220.

16 Die ersten Informationen zu diesem Problem sind leider erst mit der Zeit des Wenzels verknüpft: Crescente fide Christiana, S. 185 gibt an, dass Wenzel die Priester aus Bayern und Schwaben eingeladen hat; so auch Legenda Christiani, S. 60 f. (Kap. 6). Vita Vencezlavi ducis Bohemiae, S. 150 f. (Kap. 7) sagt, dass Wenzel lud Priester aus jedem Land. 
stimmen: Nach dem Niedergang der mährischen kirchlichen Strukturen ist praktisch keine andere Lösung vorhanden. Die Opposition der beiden Traditionen musste sogar noch nicht bedeutsam sein.

Bis 929 kann es hingegen de facto von keinen tschechisch-sächsischen Beziehungen, vor allem der kirchlichen, eine Rede sein. Spätestens seit 907, in Wirklichkeit aber seit dem Ende des 9. Jahrhunderts, ist die Reichspolitik im Allgemeinen in einer gewissen Krise gewesen. Die Peripherien wurden so notwendigerweise noch weiter vom Kern des Reiches entfernt. Die bayerischen Hegemonen dürften so den Přemysliden noch näherkommen, was auch die Koexistenz ihrer Kirche fördern könnte. Gemeinsam konnten aber die bayerischen und tschechischen Herrscher nur die Zunahme der Macht der ungarischen Stammesunion beobachten ${ }^{17}$. Das Jahr 907 markierte die Krisenkulmination dieses Trends ${ }^{18}$. Das von den Niederlagen geschwächte ostfränkische Reich ist seither zu einem regelmäßigen Ziel (nicht nur) der ungarischen Überfälle geworden, und in den nächsten 15-20 Jahren kämpfte es in gegenseitigen Streitigkeiten und suchte nach einer eitlen Verteidigung gegen die verheerenden Überfälle aus dem Osten (aber auch aus dem Norden).

Allerdings konnten die Přemysliden in Bayern dauerhaft einen natürlichen politischen Partner sehen. Sowohl Böhmen als auch Bayern lagen am Anfang des Weges der ungarischen Überfälle, und wenn sie nicht das nächste Opfer militärischer Expeditionen aus Pannonien sein sollten, mussten sie ein gewisses Maß an Verteidigung suchen, aber auch Koexistenz, die die bayerischen und tschechischen Interessen miteinander verbinden könnte. Dušan Tř̌eštík schilderte offensichtlich recht die Möglichkeit der Zusammenarbeit zwischen den Přemysliden und Arnulf von Bayern zur Zeit, als der Herzog versucht hatte, einen alternativen Kraftkern gegen die Hegemonen von Franken und später von Sachsen zu schaffen ${ }^{19}$. Die Tschechen sind manchmal der offenen Zusammenarbeit mit den Ungarn verdächtig ${ }^{20}$, aber es muss gesagt werden, dass auch die bayerischen Herrscher auf eine Kooperation oder zumindest auf gezwungene Kompromisse zurückgriffen $^{21}$, und dass alle unsere Quellen nicht einmal den Tschechen die Schuld an der Perfidie, oder dem Abfall von der bayerischen Kirche zuschrieben.

Die Kontinuität des kirchlichen Interesses der Regensburger Diözese für das tschechische Territorium ist das Hauptargument, das die Idee der engen tschechisch-bayerischen Beziehungen in dieser Epoche unterstützt. Man kann sogar sagen, dass die kirchlichen Kontakte zur Regensburger Diözese das sein könnten, was die Beziehung zwischen den Přemysliden und ihren bayerischen Nachbarn definiert hat. Der Bischofssitz von Regens-

17 Maximilian DIESENBERGER, Baiern, das Ostrfränkische Reich und die Ungarn bis zur Schlacht von Pressburg 907, in: Roman Zehetmayer (Hg.), Schicksalsjahr 907: die Schlacht bei Pressburg und das frühmittelalterliche Niederösterreich. St. Pölten 2007, s. 31-43.

18 Die letzte Literatur zum Thema ist zusammengefasst in den Sammelbücher Zehetmayer (Hg.), Schicksalsjahr 907 und Tatiana ŠTEFANOVIČOVÅ - Drahoslav HULÍNEK (Hgg.), Bitka pri Bratislave v roku 907 a jej význam pre vývoj stredného Podunajska. Bratislava 2008.

19 So interpretiert die bescheidenen Nachrichten der Quellen TŘEŠTÍK, Počátky Přemyslovců, S. 357-360.

20 Siehe Michal LUTOVSKÝ, Jižní Čechy v raném středověku: slovanské osídlení mezi Práchní a Chýnovem. České Budějovice 2011, S. 212; unsicher scheint die Nachricht von Adam von Bremen, Gesta Hammaburgensis ecclesiae pontificum, hg. von Georg Heinrich PERTZ u. a., in: MGH Scriptores (in Folio). Bd. 7: Chronica et gesta aevi Salici. Hannover 1846, S. 300 f. [I 52]), dass die Tschechen wirklich an einem ungarischen Überfall teilgenommen sind.

${ }^{21}$ Liudprand von Cremona (Antapodosis, hg. von Joseph BECKER, in: Liutprandi opera [MGH Scriptores rerum Germanicarum in usum scholarum separatim editi. Bd. 41]. Hannover/Lepizig 1915, S. 46 [II 19]) berichtet, dass Arnulf sich für lange Zeit auf ungarische Hilfe verließ. 
burg war kurz vor 895 von einem neuen Bischof Tuto besetzt, dessen Bischofsamt bis 930 dauerte $^{22}$. Es ist vielleicht diese Person, die für die eindeutige kirchliche Orientierung der Přemysliden auf den bayerischen Nachbar verantwortlich gemacht werden kann.

Die politische Situation im ostfränkischen Reich begann sich um 920 zu ändern. Nach dem Tod von Konrad I kam sein gewesener Konkurrent Heinrich der Finkler überraschend reibungslos auf den Thron ${ }^{23}$. Die fränkisch-sächsische Allianz feierte bald ihre ersten Erfolge, und Heinrich konnte das Reich in der Form von der zweiten Hälfte des 9. Jahrhunderts während der Herrschaft der letzten Karolinger wiederaufbauen. Bayern und Schwaben erhielt er in seine Macht indirekt, anscheinend nicht nur wegen einer Reihe von militärischen Demonstrationen der Macht, sondern vielmehr wegen der komplizierten Verhandlungen und politischen Kompromisse ${ }^{24}$, die ihm erlaubten, seine Souveränität zu behaupten, auf die er und seine Nachkommen weiter bauen konnten. Der bayerische Herzog bewahrte damals eine gewisse Unabhängigkeit, die vor allem durch eine Beschützerposition gegen die bayerische Kirche verwirklicht wurde.

Es gibt keinen Grund, die Böhmen nicht in diese Stellung des bayerischen Herzogs gegen die bayerische Kirche einzuschließen. Paradoxerweise war es jetzt Bischof Tuto, wer Heinrichs Interessen in Bayern am nächsten war. Für ihn und die anderen bayerischen Kleriker musste nämlich Arnulfs Schutzhand über die Kirche zu lästig sein. In Böhmen ist zugleich der jüngere Fürst Vratislav gestorben, was mit einem politischen Streit zwischen seiner Mutter und der Witwe verbunden ist ${ }^{25}$. Leider werden alle Versuche, diese interne Kontroverse mit Außenpolitik zu verbinden, nur im Rahmen der Theorie bestehen. Wahrscheinlich ist der Kontakt der Fürstin-Witwe Drahomíra mit den verwandten elbischen Slawen, die sich damals schon tatsächlich von der sächsischen Hegemonie bedroht fühlen konnten ${ }^{26}$. Es scheint auch, dass die alternde Ludmila eine engere Beziehung zu dem bayerischen Klerus hatte, der aber, wie oben gesagt, paradoxerweise eher mit der politischen Position von Heinrich dem Finkler als dem bayerischen Herzog Arnulf verknüpft werden könnte ${ }^{27}$. Wir wissen mit Sicherheit lediglich das, dass nur ein Jahr nach dem mörderischen Höhepunkt des Streits zwischen den beiden Fürstinnen Arnulf selbst nach Böhmen $\mathrm{kam}^{28}$ und anscheinend den Zustand hier unter Berücksichti-

22 Josef KLOSE, Tuto, Bischof von Regensburg und Abt von St. Emmeram (894-930), in: Georg Schwaiger (Hg.), Lebensbilder aus der Geschichte des Bistums Regensburg. Bd.1. Regensburg 1989, s. 81-92.

23 Siehe zum Beispiel Widukindi monachi Corbeienses Rerum gestarum Saxonicarum, S. 39 (I 26) und Gerd ALTHOFF, Die Ottonen: Königsherrschaft ohne Staat. Stuttgart 2013, s. 37-45.

24 Zur Praxis der Heinrichs Regierung siehe eine interessante Studie: Susanne KAEDING - Britta KÜMMERLEN - Kerstin SEIDEL, Henrich I.: ein „Freundschaftskönig?“, in: Concilium Medii Aevi 3 (2000), S. 265-326.

25 Crescente fide Christiana, S. 184; Legenda Christiani, S. 26-39 und Legende Fuit in provintia Boemorum, hg. von Václav CHALOUPECKÝ, in: Prameny X. století legendy Kristiánovy o svatém Václavu a svaté Ludmile. Praha 1939, S. 459-481; hier S. 470-474. Siehe auch TǨEŠTÍK, Počátky Přemyslovců, S. 369-374 und Nad’a PROFANTOVÁ, Kněžna Ludmila: vládkyně a světice, zakladatelka dynastie. Praha 1996, S. 99-103.

26 Der Fortsetzer Reginos, (Adalberti) Continuatio Reginonis, hg. von Friedrich KURZE, in: Reginonis abbatis Prumiensis Chronicon cum continuatione Treverensi (MGH Scriptores rerum Germanicarum in usum scholarum separatim editi. Bd. 50). Hannover 1890, S. 154-179; hier S. 156 (a. 921)) schreibt, dass Heinrich zu dieser Zeit: „reprimendae Sclavorum sevitiae fortiter insistit. “ Leider wissen wir nicht, welche Slawen er meint und außerdem steht er mit dieser Nachricht allein.

27 TŘEŠTÍK, Počátky Přemyslovců, S. 369.

28 Annales Ratisbonenses, in: Georg Heinrich PERTZ u. a. (Hg.). Scriptores (in Folio). Bd. 17: Annales aevi Suevici. Hannover 1861, S. 577-590, hier S. 583 (a. 922). 
gung seiner Interessen wiederherstellte. Manchmal ist dieser Zug mit dem Thronaufstieg vom Fürst Wenzel verbunden, der sich als etwa Fünfzehnjähriger schon von der Aufsicht seiner Mutter befreien sollte ${ }^{29}$.

So können wir während der zwanziger Jahre des 10. Jahrhunderts mit Sicherheit die ersten, wenn auch indirekten Kontakte der Tschechen mit Sachsen und vielleicht mit seiner Kirche erwarten. Die slawischen Verwandten der tschechischen Fürsten sind schon in ständigen Kontakt mit der sächsischen Streitmacht gekommen, die unter dem Druck der ungarischen Überfälle versucht hat, das Gebiet zu konsolidieren. Es war nicht nur ein militärischer Kampf - die hevellerische Fürstdynastie gilt damals als vielleicht christlich $^{30}$, und die Ausbreitung eines neuen Glaubens, neben den Beziehungen zu den christlichen Tschechen, konnte auch von den sächsischen Geistlichen versorgt werden.

Das Jahr 929 scheint wirklich ein starker Durchbruch zu sein: Heinrich der Finkler beschloss, seine Kräfte gegen die Ungarn in einer Kampagne zu testen, die seine Hände im Norden befreien und die Feinde der möglichen slawischen Verbündeten berauben sollte $^{31}$. Kritisch war die Situation für die Daleminzier, die für die offenen Verbündeten der Ungarn bezahlt wurden. Ihr Sitz wurde wörtlich geplündert. Etwas mehr „zivilisiert“ benahmen sich die Sachsen in Brandenburg (vielleicht, weil die Fürsten bereits das Christentum bekennen konnten). Ganz als „friedlich“ beschreiben die Quellen die Situation, als die sächsischen Truppen in Böhmen eintraten. Obwohl die Annalen diese Aktion als eine wirklich militärische Operation sehen ${ }^{32}$, erwähnt der ausführliche Bericht von Chronisten Widukind von Corvey überhaupt keinen wirklichen Kampf. Nur die Unterwerfung des tschechischen Fürsten. Wenzel, der in diesen Berichten eine namenlose Figur ist, traf nicht nur Heinrich den Finkler, sondern auch Arnulf von Bayern ${ }^{33}$, der diesen Teil des Zugs unterstützte. Es ist also möglich, dass es in Prag damals in erster Linie eine Art wenn auch kraftinduzierte - trilaterale Handlung gab, in der das Verhältnis der Tschechen mit den Reichsherrschern neu definiert wurde. Die wahrscheinliche Gebühr, die bis dahin an Bayern gezahlt wurde ${ }^{34}$, wurde den Sachsen zugeschrieben, und wir können auch über andere Beziehungen sprechen, die sich aus der Reichsperspektive geändert haben.

Es war sicherlich nicht möglich - rechtlich gesprochen -, dass Böhmen in diesem Zusammenhang aus der kirchlichen Zugehörigkeit zum bayerischen Regensburg ausstieg. Jedoch haben wir bereits erwähnt, dass das bayerische Bischofsamt gegenüber Heinrichs Plänen eher wohlwollend eingestellt sein könnte. Die engere Beziehung zwischen Böhmen und Sachsen zu dieser Zeit hätte eine Möglichkeit für den sächsischen Klerus sein können. Der Klerus war sicherlich bei Heinrichs Kampagne anwesend und konnte an der Zeremonie teilnehmen, die Quellen leider mit großem Abstand und indirekt bele-

29 Vgl. TŘEŠTíK, Počátky Přemyslovcư, S. 196, wo er aber diese Theorie auch kritisch bewertet.

30 So Christian LÜBKE, Machtfaktoren im Osten des Ottonischen Reiches in der Zeit Boleslavs II., in: Petr Sommer (Hg.), Boleslav II.: der tschechische Staat um das Jahr 1000. Praha 2001, S. 385-395; hier S. 388.

31 Widukindi monachi Corbeienses Rerum gestarum Saxonicarum, S. 49 f. (I 35).

32 Continuatio Reginonis, S. 158 (falsch zum Jahr 928); Annales Ratisbonenses, S. 583 (a. 929).

33 Annales Ratisbonenses, wie oben.

34 Solche Nachricht vermittelt der Chronist Cosmas (Die Chronik der Böhmen des Cosmas von Prag (Cosmae Pragensis Chronica Boemorum) (MGH Scriptores rerum Germanicarum. Nova series. Bd. 2), hg. von Berthold BRETZHOLZ. Berlin 1923, S. 93 f. [II, 8]). Es ist jedoch nicht sicher, ob diese Gebühr kontinuierlich bezahlt wurde - vgl. z. B. Jakub RAZIM, Vèrní Přemyslovci a barbarští Čechové: českoř́šské vztahy v raném a vrcholném středověku. Praha 2017, S. 220-223. 
gen $^{35}$. Wenzel schloss damit wahrscheinlich eine Allianz mit Heinrich und einen Eid auf die Reliquien des sächsischen Heiligen - Veit - ablegte. Ein solches Verfahren müsste im Voraus vorbereitet werden, und so ist es möglich, dass die Kooperationsbereitschaft von Wenzel bereits erwartet wurde. Ein Teil der Reliquien konnte Wenzel wirklich als Geschenk und zugleich als eine Erinnerung an sein Engagement in dieser Zeremonie anvertraut werden. Wenn die späte Tradition uns nicht täuscht, können wir eine weitere Annahme über diese Veranstaltung machen - die Aufbewahrung der Reliquien in Prag erforderte nicht nur den Bau des Heiligtums, das natürlich die spätere Prager Bischofskirche ist ${ }^{36}$, sondern wahrscheinlich auch einen unmittelbaren Kontakt in der Form der Ankunft der sächsischen Kleriker gebracht hat. Wir können so weit gehen, dass wir eine besondere Institution markieren - das sächsische Kloster in Corvey, woher die Reliquien fast sicher kamen ${ }^{37}$. Die Verknüpfung von Corvey mit der Slawenmission kann allgemein angenommen werden, so dass man davon ausgehen darf, dass nach der Hinterlegung der Reliquien des Sachsen- und Reichspatrons in Prag eine Form der Missionsplattform mit den „Humanressourcen“ der sächsischen Mönche gegründet wurde. Eine gewisse Art der Dualität der bayerisch-sächsischen kirchlichen Bindungen zu Böhmen drückt die interessante Tatsache aus, dass die Weihe der heiligen Veits-Rotunde angeblich während des Festes des heiligen Emmeram stattfand ${ }^{38}$. Vielleicht deutet diese Tatsache darauf hin, dass es in der ausländischen Orientierung des tschechischen kirchlichen Lebens zu dieser Zeit wirklich große Veränderungen gab. Heinrich der Finkler unterwarf seiner Macht zugleich auch andere slawische Stämme, und es war klar, dass in der nächsten Epoche die Verbreiter des Christentums unter den Slawen in der einen oder anderen Weise die Sachsen werden. Darüber hinaus wäre es noch möglich, dass der bayerische Klerus Heinrichs Schutz als das Gegengewicht gegen die nicht allzu begrüßende Dominanz der bayerischen Herzöge sah. Darum könnte noch Tuto auch der möglichen Aktionen der sächsischen Missionare in Böhmen geneigt sein, was normalerweise eine kanonische Notwendigkeit wäre. Ein Ausdruck der Ehrfurcht zu dem heiligen Emmeram konnte eigentlich eine Kompromisserinnerung an die wahre kirchliche Souveränität über die Sankt-Veits-Kirche.

Wenzel hatte zur Zeit von Heinrichs Feldzug nur sechs Jahre seines Lebens vor sich. Die meisten Informationen über seine praktische Politik stammen aus einem sehr unzuverlässigen Quellen - der Hagiographie. Die ursprünglich teilweise bayerische Hagiographie betont nur die bayerischen und schwäbischen Spuren in der tschechischen Kirche der Wenzels Zeit. Gumpolds Erwähnung, dass er Priester aus der ganzen Welt eingeladen hat, ist leider nur als Übertreibung zu verstehen ${ }^{39}$.

Die Epoche nach dem plötzlichen und gewaltsamen Tod von Wenzel ist in erster Linie nochmal nur in hagiographischen Quellen beschrieben, aber wir können diese Informa-

35 Siehe die spätere Wenzelslegende Ut annuncietur, hg. von Paul DEVOS, in: Le dossier de S. Wenceslas dans un manuscript du XIII siècle (Codex Bollandianus 433), in: Annalecta Bollandiana 82, 1964, s. 87-131; hier S. 112 f. (Kap. 15) und der Kommentar von TŘEŠTíK, Počátky Přemyslovců, S. 413 f.

36 Das Gebäude wurde zuletzt bewertet von Dalibor PRIX, Počátky sakrální architektury v Čechách, in: Ivo Štefan - Martin Wihoda (Hgg.), Kostel Panny Marie na Pražském hradě: dialog nad počátky krestanství v Čechách. Praha 2018, S. 172-205; hier S. 190 ff. und von Jana MAŘíKOVÄ-KUBKOVÁ, Úloha kultu a církevních center ve formování Pražského hradu v raném středověku, in: ebd., S. 100-130; hier S. 116-121.

37 Siehe die Studie von Daniel Ziemann in diesem Band.

38 Die Chronik der Böhmen, S. 38 (I 18) und vgl. TřE ŠTíK, Počátky Přemyslovců, S. 254.

39 Siehe Anm. 11. 
tion bereits mit anderen Quellen vergleichen. Die Erwähnung der Verfolgung der Priester durch den heftigen Bruder des Heiligen ${ }^{40}$ kann neben den Informationen über den vierzehnjährigen Krieg zwischen Boleslav und König Otto von Ostfranken gestellt werden ${ }^{41}$. Es ist wahrscheinlich, dass die Verfolgung der Priester eher als Boleslavs schlechte Beziehung zum fremden Klerus erklärt werden kann, der aus den seinem Reich de facto feindlichen Gebieten kam. Symptomatisch ist es, dass Otto I nach einem eher milden Ende des eher kalten Krieges mit Boleslav im Jahre $950^{42}$ Böhmen noch einmal der Obhut seines Bruders, des Herzogs von Bayern, anvertrauen wollte ${ }^{43}$. Dabei vergaß er nicht, dem Kloster St. Emmerams in Regensburg mehr Vermögen zu geben, das dann den Ertrag aus dem Vermögen in eine erneuerte Verwaltung des böhmischen Teils der Regensburger Diözese investieren konnte ${ }^{44}$. Die ehrgeizige Innenpolitik von Boleslav I. beruhte von nun an auf dem Ausbau der politischen Macht in Böhmen und auch jenseits ihrer Ostgrenze $^{45}$. Das war sicherlich mit der Notwendigkeit verbunden, den christlichen Einfluss durch den Bau neuer Kirchen sowie den Erwerb neuer Priester zu verbreiten. Der Chronist Cosmas verweist in diesem Zusammenhang an viele neue Kirchen, deren Bau allgemein mit der zweiten Hälfte des 10. Jahrhunderts zusammengeknüpft werden kann ${ }^{46}$.

Die Epoche der abhängigen böhmischen Kirche ging auf diese Weise langsam zu Ende. Im Zusammenhang mit der großen Reform der Reichsdiözesen erfüllten sich auch die Ambitionen der böhmischen Fürsten, die anscheinend schon länger nach irgendeiner Form der kirchlichen Unabhängigkeit gesucht haben. In einem umfangreichen System von verschiedenen Kompromissen sollte die neue Prager Diözese nicht nur von der Regensburger Verwaltung, sondern auch von der Bayerischen Provinz Salzburg in den späten sechziger Jahren des 10. Jahrhunderts getrennt werden ${ }^{47}$. Zum neuen Vorgesetzten für das neue Bistum sollte ein Mainzer Erzbischof werden, der im Gegenteil einen direkten Einfluss auf das Elbegebiet aufgeben musste. Paradoxerweise konnte die Zugehörigkeit zu dem fränkischen Erzbistum einen weiteren Einfluss und Zuzug des sächsischen Elements bedeuten, weil „Altsachsen“, vor allem sein westliches und zentrales Gebiet, immer noch ein Teil der ursprünglichen Mainzer Erzdiözese war. Die sächsischen Bistümer Verden, Paderborn, Hildesheim und Halberstadt waren dank ihrer Kontakte mit Slawen eine natürliche Quelle der menschlichen Kräfte für slawisches Böhmen (und neben Eichstätt und Würzburg war Halberstadt einer der nächsten Bischofsnachbarn des Prager Stuhls in der gesamten Mainzer Provinz). Auch sächsisches Kloster Corvey war eine Stiftung, die die Interessen ihrer Metropole verteidigte. Der dortige Chronist

40 Crescente fide Christiana, S. 187; Vita Vencezlavi ducis Bohemiae, S. 161 (Kap. 20); Legenda Christiani, S. 76 f. (Kap. 8).

41 Widukindi monachi Corbeienses Rerum gestarum Saxonicarum, S. 70 (II 3).

42 Ebd., S. 108 f. (III 7).

43 So berichtet Thietmar von Merseburg Thietmari Merseburgensis episcopi Chronicon (MGH Scriptores rerum Germanicarum. Nova series. Bd. 9), hg. von Robert HOLTZMANN. Berlin 1935, S. 40 f. [II 2]).

${ }^{4}$ Die Urkunden Konrads I., Heinrichs I. und Ottos I., hg. von Theodor SICKEL (MGH Die Urkunden der deutschen Könige und Kaiser. Bd. 1). Hannover 1879-1884, S. 207 f. (Nr. 126 [950 Juni 16]).

45 Siehe Michal LUTOVSKÝ, Bratrovrah a tvůrce státu: život a doba knížete Boleslava I. Praha 2006, insb. S. 139-144.

46 Die Chronik der Böhmen, S. 46 (I 24).

47 Siehe z. B. David KALHOUS, Záhadné počátky pražského biskupství, in: Eva Doležalová - Robert Novotný - Pavel Soukup (Hgg.), Evropa a Čechy na konci středověku: sborník př́ispěvků věnovaných Františku Šmahelovi. Praha 2004, S. 195-208. 
Widukind hat in seiner Chronik die meisten Bemerkungen über die gegründete Provinz Magdeburg, die im Nordosten die Mainzer Verwaltung und Mission ersetzte, ostentativ übergegangen ${ }^{48}$. Vielleicht aber hat Widukind einen gewissen Hinweis auf die Schaffung der Prager Diözese nicht vergessen, die in diesen Zusammenhang fiel. Er erinnert die Prinzessin Mathilde, die Hauptadressatin seiner Chronik, daran, dass sie vor allem den heiligen Vitus ehren sollte, und in den Mund des Heiligen legt er bei dieser Gelegenheit eine interessante Phrase: Dem Gottes Schutz werden von allen die empfohlen, die „sich mit seinem Namen prunken wollen "49. Das ist eine offensichtliche Andeutung auf die dem Vitus gewidmeten Kirchen, wie die Corveyer und - zur Zeit der Chronik - auch Prager Kirche ${ }^{50}$. Es ist auch nennenswert, in dieser Hinsicht die ambivalente Haltung des Chronisten zur Gestalt des heiligen Wenzels zu erwähnen. Er betont seine Frömmigkeit und sogar einige Anzeichen von Wundern, aber zur gleichen Zeit weigert er sich die ganze Sache direkt zu schildern ${ }^{51}$. Diese besondere Haltung könnte durch die zweifache Beziehung von Widukind zur Errichtung der Prager Diözese erklärt sein: Einerseits könnte die Verehrung von Wenzel als ein Argument für den weiteren Aufstieg Prags und damit für die Förderung des Ruhms von Vitus, Corvey und der Corveyer Metropole in Mainz dienen, auf der anderen Seite konnte der neue Heilige das Sankt-Vitus-Patrozinium überschatten. Widukind beschrieb daher die ganze Sache vielleicht in einem ziemlich seltsamen Kompromiss.

Als der Austausch auf dem Bischofsstuhl in Regensburg die Vollendung der komplexen Veränderungen in der Struktur der Kirche erlaubte, und die Stille der Nachfolgestreitigkeiten nach dem Tod von Otto I den Weg für die Weihe des ersten Prager Bischofs öffnete, saß der Sachse Thietmar auf dem Prager Stuhl ${ }^{52}$. Cosmas sagt uns, dass er ein Mönch war, der die Landessprache kannte, was darauf hindeutet, dass er schon lange unter den Slawen wirksam war. Der Chronist deutet auch an, dass Thietmar nach Prag kam, bevor er zum Bischof wurde. Seine genaue Zugehörigkeit zu einem bestimmten Kloster ist nicht bekannt, aber Corvey, mit seiner Bedeutung, ist eine sehr wahrscheinliche Möglichkeit. Wenn wir uns die Liste der Mönche des Corveyer Klosters anschauen ${ }^{53}$, finden wir natürlich mehrere Personen mit dem Namen Thietmar, es war ein üblicher Name. Keiner von ihnen hat eine Nachschrift „Bischof“, wie wir in der gleichen Quelle bei Thiddag von Prag lesen, der so klar identifiziert ist. Allerdings ist es interessant, dass einer der zwei im Alter entsprechenden Thietmars natürlich ein Altersgenosse von Chronist Widukind war, was das Interesse des Chronisten von „St. Vitus Patrozinien“ noch besser erklären würde. Kommt der Mönch Thietmar aus Corvey, musste ihm Widukind auf jeden Fall kennenlernen.

48 Siehe Helmut BEUMANN, Widukind von Korvei: Untersuchungen zur Geschichtsschreibung und Ideengeschichte des 10. Jahrhunderts. Weimar 1950, S. $183 \mathrm{f}$.

49 Widukindi monachi Corbeienses Rerum gestarum Saxonicarum, S. 47 f. (I 34).

50 So auch Helmut BEUMANN, Entschädigungen von Halberstadt und Mainz bei der Gründung des Erzbistums Magdeburg, in: Klaus Herbers - Hans-Henning Kortüm - Carlo Servatius (Hgg.), Ex ipsis rerum documentis: Beträge zur Mediävistik: Festschrift für Harald Zimmermann zum 65. Geburtstag. Sigmaringen 1991, S. 383-398; hier S. 390-398.

51 Widukindi monachi Corbeienses Rerum gestarum Saxonicarum, S. 50 f. (I 35).

52 Die Chronik der Böhmen, S. 44 ff. (I 23 f.).

${ }^{53}$ Catalogus Abbatum et Nomina Fratrum Corbeiensium, hg. von Oswald HOLDER-EGGER, in: MGH Scriptores (in Folio). Bd. 13: Supplementa tomorum I-XII, pars I. Hannover 1881, S. 274-277, hier S. 276. 
Die sächsische „Mission“ in Böhmen musste am Ende des 10. Jahrhunderts ihre soliden Fundamente haben, so ist es logisch, dass bei der Suche nach einem erfahrenen Arzt, der mit der Krankheit des tschechischen Fürsten fertig werden sollte, sein Umkreis die Verbindung mit dem Sächsischen Kloster in Corvey benutzte ${ }^{54}$. Vielleicht hätte seinen jüngeren Mitbruder schon Thietmar von Prag nach Böhmen gebracht - der auf jeden Fall seinen Eintritt zum Kloster erlebt hatte. Neben dem unmittelbaren sächsischen Einfluss in Form von zwei Bischöfen ist noch das sächsische Element zu erwähnen, mit dem der tschechische Bischof Vojtěch durch die Schule in Magdeburg in Kontakt kam ${ }^{55}$. Es war in seiner Zeit sicherlich eine wichtige, obwohl immer noch ziemlich junge Institution. Der Erzbischof Adalbert, der der erste Magdeburger Erzbischof und sicher auch der geistliche Pate von Vojtěch war ${ }^{56}$, war jedoch Lotharingischer Herkunft ${ }^{57}$. Über den Ursprung des unmittelbaren Lehrers des heiligen Vojtěch, des berühmten Ohtrich, der vergeblich versucht hat, zum Magdeburger Erzbischof zu werden ${ }^{58}$, wissen wir leider überhaupt nichts ${ }^{59}$. Neben dieser beiden Figuren traf sich der Bischof Vojtěch innerhalb seines Studiums in Magdeburg und auch seiner Anwesenheit in Prag als ein Suffragan des Mainzer Erzbischofs, der noch für mehrere sächsische Diözesen verantwortlich war, mit einer großen Anzahl sächsischer Kleriker. Viele von ihnen wirkten unter den Slawen, besonders die sächsischen Verwalter der neuen Diözesen. Thietmar von Merseburg, der unsere Quellen über diese Zeit abschließt, rühmte sich der Kenntnis der slawischen Sprache ${ }^{60}$, obwohl er die eigenen Schafe dieser Nation insgesamt verachtete ${ }^{61}$. Er allein ist jedoch ein Beispiel dafür, dass selbst der weltliche Kleriker seiner Prägung ein Teil der sächsischen Mission werden könnte, die unter den Slawen und auch in Böhmen gefördert wurde.

Sachsen macht, auf den ersten Blick, keinen Eindruck als ein natürlicher Partner der tschechischen Länder, in unserer historiographischen Tradition hat es eher eine feindliche Position. Trotzdem muss es betont werden, dass die Ursprünge der tschechischen christlichen Kirche und insbesondere der unabhängigen Prager Diözese einen großen sächsischen Fußabdruck tragen. Unter den Klerikern, die am Přemyslid-Hof auftauchten, erschienen die Sachsen offensichtlich regelmäßig, sonst konnte es nicht so einen überraschenden Zufall geben, dass eben zwei von ihnen einen Bischofssitz in Prag besetzten. Darüber hinaus weisen die Quellen auf eine gewisse Zuneigung für die beiden in der lokalen Umgebung hin. Dies deutet auf eine Beziehung hin, die nicht natürlich und innerhalb kurzer Zeit entstand. Bischof Thiddag, der vor tausend Jahren verstorben war, war einer der unbestrittenen Vertreter des sächsischen spirituellen Elements in Böhmen. Sein Nachfolger Ekhard kam nach Prag als Böhmen-kundig aus die Abtei von Naumburg an der Saale ${ }^{62}$. Sein Name und Lebenslauf deuten auf die Zugehörigkeit zur Markgraffa-

\footnotetext{
54 Thietmari Chronicon, S. 468 f. (VII 56).

55 Siehe z. B. S. Adalberti Pragensis episcopi et martyris Vita prior, hg. von Jadwiga KARWASINSKA, in: Monumenta Poloniae Historica. Series nova. Bd. 4. Teil 1. Warszawa 1962, S. 5 ff. (Kap. 3).

56 Ebd.

57 Dietrich CLAUDE, Adalbert, Erzbischof von Magdeburg seit 968 ( $† 981$ ), in: Lexikon des Mittelalters 1 (2003), Sp. $98 \mathrm{f}$.

58 Siehe Thietmari Chronicon, S. 110-115 (III 12 f.).

59 Knut GÖRICH, Ohtrich († 981), in: Lexikon des Mittelalters 6 (2003), Sp. 1380.

60 Thietmari Chronicon, S. 86 f. (II 37); S. 194 f. (IV 55) und S. 498 f. (VIII 4).

61 Siehe zum Beispiel die erste Referenz in der vorherigen Anmerkung.

62 Thietmari Chronicon, S. 478 f. (VII 65).
} 
milie aus Meißen und damit auf die fortdauernde sächsische (hier genauer die sächsischthüringische) Spur in der frühen tschechischen christlichen Kirche.

\section{Danksagungen}

Diese Studie ist im Rahmen des Universitätsprogramms PROGRES Q 09: Geschichte der Schlüssel zum Verständnis der globalisierten Welt erschienen.

\section{LITERATURVERZEICHNIS}

\section{Quellen}

(Adalberti) Continuatio Reginonis, hg. von Friedrich KURZE, in: Reginonis abbatis Prumiensis Chronicon cum continuatione Treverensi (MGH Scriptores rerum Germanicarum in usum scholarum separatim editi. Bd. 50). Hannover 1890, S. 154-179.

Adam von Bremen, Gesta Hammaburgensis ecclesiae pontificum, hg. von Georg Heinrich PERTZ u. a., in: MGH Scriptores (in Folio). Bd. 7: Chronica et gesta aevi Salici. Hannover 1846.

Annales Fuldenses sive Annales regni Francorum orientalis, hg. von Friedrich KURZE (MGH Scriptores rerum Germanicarum in usum scholarum separatim editi. Bd. 7). Hannover 1891.

Catalogus Abbatum et Nomina Fratrum Corbeiensium, hg. von Oswald HOLDER-EGGER, in: MGH Scriptores (in Folio). Bd. 13: Supplementa tomorum I-XII, pars I. Hannover 1881, S. 274-277.

Die Chronik der Bohmen des Cosmas von Prag (Cosmae Pragensis Chronica Boemorum), hg. von Berthold BRETZHOLZ (MGH Scriptores rerum Germanicarum. Nova series. Bd. 2). Berlin 1923.

Crescente fide Christiana. Recensio bavarica, hg. von Josef EMLER, Fontes rerum bohemicarum. Bd. 1, Praha 1873, S. 183-190.

Annales Ratisbonenses, in: Georg Heinrich PERTZ u. a. (Hg.). Scriptores (in Folio). Bd. 17: Annales aevi Suevici. Hannover 1861, S. 577-590.

Fuit in provintia Boemorum, hg. von Václav CHALOUPECKÝ, in: Prameny X. století legendy Kristiánovy o svatém Václavu a svaté Ludmile. Praha 1939, S. 459-481.

Legenda Christiani: Vita et passio Sancti Wenceslai et sancte Ludmile ave eis = Kristianova legenda: Život a umučení svatého Václava a jeho báby svaté Ludmily, hg. von Jaroslav LUDVÍKOVSKÝ. Praha 1978.

Liudprand von Cremona, Antapodosis, hg. von Joseph BECKER, in: Liutprandi opera (MGH Scriptores rerum Germanicarum in usum scholarum separatim editi. Bd. 41). Hannover/Lepizig 1915, S. 1-158.

S. Adalberti Pragensis episcopi et martyris Vita prior, hg. von Jadwiga KARWASIŃSKA, in: Monumenta Poloniae Historica. Series nova. Bd. 4. Teil 1. Warszawa 1962.

Thietmari Merseburgensis episcopi Chronicon, hg. von Robert HOLTZMANN (MGH Scriptores rerum Germanicarum. Nova series. Bd. 9). Berlin 1935.

Die Urkunden Konrads I., Heinrichs I. und Ottos I., hg. von Theodor SICKEL (MGH Die Urkunden der deutschen Könige und Kaiser. Bd. 1). Hannover 1879-1884.

Ut annuncietur, hg. von Paul DEVOS, in: Le dossier de S. Wenceslas dans un manuscript du XIII siecle (Codex Bollandianus 433), in: Annalecta Bollandiana 82, 1964, s. 87-131.

Vita Vencezlavi ducis Bohemiae, hg. von Josef EMLER, Fontes rerum bohemicarum. Bd 1. Praha 1873, S. $146-166$.

Widukindi monachi Corbeienses Rerum gestarum Saxonicarum libri III, neu bearb. von Paul HIRSCH Hans-Eberhard LOHMANN (MGH Scriptores rerum Germanicarum in usum scholarum separatim editi. Bd. 60). Hannover 1935.

\section{Literatur}

Gerd ALTHOFF, Die Ottonen: Königsherrschaft ohne Staat. Stuttgart 2013.

Helmut BEUMANN, Entschädigungen von Halberstadt und Mainz bei der Gründung des Erzbistums Magdeburg, in: Klaus Herbers - Hans-Henning Kortüm - Carlo Servatius (Hgg.), Ex ipsis rerum 
documentis: Beträge zur Mediävistik: Festschrift für Harald Zimmermann zum 65. Geburtstag. Sigmaringen 1991, S. 383-398.

Helmut BEUMANN, Die Ottonen. Stuttgart/Berlin/Köln 2000.

Helmut BEUMANN, Widukind von Korvei: Untersuchungen zur Geschichtsschreibung und Ideengeschichte des 10. Jahrhunderts. Weimar 1950.

Dietrich CLAUDE, Adalbert, Erzbischof von Magdeburg seit 968 (†981), in: Lexikon des Mittelalters 1 (2003), Sp. 98 f.

Maximilian DIESENBERGER, Baiern, das Ostrfränkische Reich und die Ungarn bis zur Schlacht von Pressburg 907, in: Roman Zehetmayer (Hg.), Schicksalsjahr 907: die Schlacht bei Pressburg und das frühmittelalterliche Niederösterreich. St. Pölten 2007, S. 31-43.

Susanne KAEDING - Britta KÜMMERLEN - Kerstin SEIDEL, Henrich I.: ein „Freundschaftskönig?“‘, in: Concilium Medii Aevi 3 (2000), S. 265-326.

David KALHOUS, Záhadné počátky pražského biskupství, in: Eva Doležalová - Robert Novotný Pavel Soukup (Hgg.), Evropa a Čechy na konci středověku: sborník př́ispěvků věnovaných Františku Šmahelovi. Praha 2004, S. 195-208.

Josef KLOSE, Tuto, Bischof von Regensburg und Abt von St. Emmeram (894-930), in: Georg Schwaiger (Hg.), Lebensbilder aus der Geschichte des Bistums Regensburg. Bd.1. Regensburg 1989, S. 81-92.

Christian LÜBKE, Machtfaktoren im Osten des Ottonischen Reiches in der Zeit Boleslavs II., in: Petr Sommer (Hg.), Boleslav II.: der tschechische Staat um das Jahr 1000. Praha 2001, S. 385-395.

Michal LUTOVSKÝ, Bratrovrah a tvưrce statu: život a doba knižete Boleslava I. Praha 2006.

Michal LUTOVSKÝ, Jižní Čechy v raném středověku: slovanské osídlení mezi Práchní a Chýnovem. České Budějovice 2011.

Jana MAŘíKOVÁ-KUBKOVÁ, Úloha kultu a církevních center ve formování Pražského hradu v raném středověku, in: Ivo Štefan - Martin Wihoda (Hgg.), Kostel Panny Marie na Pražském hradě: dialog nad počátky křestanství v Čechách. Praha 2018, S. 100-113. František PALACKÝ, Geschichte von Bohmen: grosstentheils nach Urkunden und Handschriften. Band 1: Die Urgeschichte und die Zeit der Herzoge in Bohmen bis zum Jahre 1197. Prag 1836.

Hans PATZE, Burchard, Graf und Markgraf von Thüringen (†909), in: Lexikon des Mittelalters 2 (2003), Sp. 942.

Dalibor PRIX, Počátky sakrální architektury v Čechách, in: Ivo Štefan - Martin Wihoda (Hgg.), Kostel Panny Marie na Pražském hradě: dialog nad počátky křestanství v Čechách. Praha 2018, S. 172-205.

Nada PROFANTOVÁ, Kněžna Ludmila: vládkyně a světice, zakladatelka dynastie. Praha 1996.

Jakub RAZIM, Věrní Přmyslovci a barbaršti Čechové: českoříšské vztahy v raném a vrcholném středověku. Praha 2017.

Jiří SLÁMA, Střední Čechy v raném středověku. Bd. 3: Archeologie o počátcích přemyslovského státu. Praha 1988.

Wilhelm STÖRMER, Die konradinisch-babenbergische Fehde um 900: Ursachen, Anlaß, Folgen, in: Hans-Werner Goetz - Simon Elling (Hgg.), Konrad I.: auf dem Weg zum Deutschen Reich?. Bochum 2006, S. 169-184.

Ivo ŠTEFAN, Velká Morava, počátky přemyslovských Čech a problém kulturní změny, in: Jiří Macháček Martin Wihoda (Hgg.), Pád Velké Moravy aneb Kdo byl pohřben v hrobu 153 na Pohansku u Břeclavi. Praha 2016, S. 190-231.

Ivo Štefan - Martin Wihoda (Hgg.), Kostel Panny Marie na Pražském hradě: dialog nad počátky křestanství $v$ Čechách. Praha 2018.

Tatiana Štefanovičová - Drahoslav Hulínek (Hgg.), Bitka pri Bratislave v roku 907 a jej význam pre vývoj stredného Podunajska. Bratislava 2008.

Dušan TŘEŠTÍK, Bořivoj und Svatopluk: die Entstehung des böhmischen Staates und Großmähren, in: Josef Poulík - Bohuslav Chropovský (Hgg.), Grossmähren und die Anfänge der tschechoslowakischen Staatlichkeit. Praha 1986, S. 311-344.

Dušan TŘEŠTÍK, Od prríchodu Slovanů k ,řřši“ českých Boleslavů, in: Petr Sommer - Dušan Třeštík Josef Žemlička (Hgg.), Přemyslovci: budování českého státu. Praha 2009, S. 61-96.

Dušan TřEŠTÍK, Počátky Přemyslovců: vstup Čechu do dějin (530-935). Praha 1997.

Roman Zehetmayer (Hg.), Schicksalsjahr 907: die Schlacht bei Pressburg und das frühmittelalterliche Niederösterreich. St. Pölten 2007. 